A search through the literature has not revealed any other case of malignant tumour of the thymus presenting as a single extrapleural metastasis.

We are indebted to Mr. J. R. Belcher and Dr. K. F. W. Hinson for their help in this case.

Philip Ellman, M.D., F.R.C.P., D. C. Hodgson, M.B., B.S., D.A.,

Chest Unit, Plaistow Hospital, London, and the London Chest Hospital.

REFERENCES

Bratton, A. B. (1948). Brit. med. J., 2, 96.

Claggett, O. T., and Eaton, L. M. (1943). Surg. Clin. N. Amer., 23, 1076 Ewing. J. (1940). Neoplastic Diseases: Treatise on Tumours, 4th ed. p. 1160. Philadelphia.

Keynes, G. (1946). Brit. J. Surg., 33, 201

(1955). Ibid., 42. 449 .

Murray, N. A.. and McDonald. J. R. (1945). Amer. J. clin. Path., 15, 87

Reid, H.,

Seybold, W. D., McDonald, J. R., Claggett, O. T., and Good, C. A. (1950). J. thorac. Surg., $20,195$.

PostSCRIPT. - Since this paper was written we have seen a report by B. B. Roe (J. thorac. Surg., 1957, 33, 770) of a case of thymic neoplasm in which distinct myasthenia gravis developed six weeks after total thymectomy and radical mediastinal block dissection. The author makes two assumptions which are of interest. He suggests that all the thymic tissue was removed, although we feel that it is hard to be sure of this, and that the thymus was innocent in spite of the pathological report's suggestion that it was malignant. Moreover, expert pathological opinion indicates that any thymic tissue which is even mildly suspicious should be regarded as almost certainly malignant.

\section{Meigs's Syndrome}

That ascites and hydrothorax may be associated with an ovarian fibroma is well known, but the existence of such a syndrome is probably not so widely recognized as it should be. Thus its true incidence is difficult to estimate; Meigs (1954) in a review of the literature found 84 authentic examples. I myself have previously seen three cases (Lawson, 1950), and these are included in Meigs's figures. The case now reported illustrates how readily the condition may be mistaken for inoperable malignancy. Paracentesis abdominis was performed 50 times-far oftener than in any of the cases included in Meigs's collected series.

\section{CASE REPORT}

A (nulliparous) spinster aged 57 was referred for gynaecological opinion in February, 1956. There had been no vaginal bleeding since the menopause at the age of 40 . A femoral hernia had been repaired in 1950 ; the medical history was otherwise negative. In September, 1953, blood appeared in the stools, and a surgeon diagnosed peritoneal carcinomatosis from cancer of the rectum. Soon afterwards ascites developed, and in December, 1953, paracentesis abdominis was performed for the first time. During the next two years this procedure was repeated at varying intervals, the abdomen being tapped altogether 48 times and a total of 470 pints (267 litres) of fluid aspirated. The fluid was always clear, and on one occasion it was examined bacteriologically with negative results. The patient complained of dyspnoea and ankle oedema as the fluid accumulated, but her general condition remained good.

By the summer of 1955 aspiration was required so often that the patient was admitted to hospital. Rectal bleeding had not occurred since the original episode, and there was no note that a pleural effusion had ever been detected. In January, 1956, another surgeon found a lower abdominal tumour and referred her for gynaecological examination.

Considering the long period of invalidism, the patient looked remarkably fit. The abdomen was grossly distended with fluid and there was a ventral hernia of moderate size. However, a firm, somewhat irregular, but freely mobile mass could be felt above the pubes. Vaginal examination was unsatisfactory. Rectal examination showed haemorrhoids, but no evidence of cancer. Clinical and radio- logical investigation revealed a massive right-sided pleural effusion. Systemic examination was otherwise negative. The peritoneal cavity was tapped (49th time) on February 7 , and again on the 18th, the amounts of fluid being 22 pints (12.5 litres) and 23 pints (13 litres) respectively. Paracentesis thoracis was not undertaken. A tentative diagnosis of Meigs's syndrome was made, and it was decided to perform laparotomy.

At operation on February 20 a further 20 pints (11.4 litres) of fluid was aspirated; this was a dark amber colour, but contained no obvious blood. A solid, freely mobile tumour of the right ovary was noted, the pedicle of which had undergone torsion through one-quarter of a circle. The left ovary was atrophic and the uterus normal. The tumour was removed together with the right Fallopian tube. Exploration of the abdominal cavity revealed no evidence of other disease. The greater part of the omentum was removed, as it was in places adherent to the abdominal wall and presented many foramina-presumably due to the repeated paracenteses. The ventral hernial sac was excised and the abdominal wall repaired in layers. Recovery was uneventful, and a week later clinical and radiological examination of the chest showed complete resolution of the effusion. No ascitic fluid was detected after operation. At the end of a month she looked and felt fit; nothing abnormal was found in either abdomen or chest.

The tumour was a lobulated, solid mass, measuring approximately 7 by 6 by 4 in. ( 17.5 by 15 by $10 \mathrm{~cm}$.) and weighing $4 \frac{1}{2} \mathrm{lb}$. $(2,060 \mathrm{~kg}$.). Although the vessels of the pedicle had been ligated, some $500 \mathrm{ml}$. of brownish fluid exuded from the tumour within 24 hours. Part of the tumour was prepared for histological examination; the remainder continued to exude fluid for several days. The cut surface presented many dilated vessels; a few appeared to be thrombosed, but there was no evidence of any gross circulatory complication. The histological appearances were those of a simple fibroma with generalized oedema and many cystic areas.

\section{COMMENT}

A detailed description of the syndrome is given in Meigs's article of 1954. Chief interest centres on the mechanisms whereby the fluid is produced and subsequently transmitted across the diaphragm. As regards the latter point, no new information has been elicited from the above case. There can be little doubt that the source of the fluid is the tumour itself. In all four personal examples the neoplasm was so moist that "waterlogged" would not be an unfair description. Two of the tumours exuded fluid amounting to about one-quarter the total weight during a period of 24 hours; in one the vessels of the pedicle were not clamped and in the other they were ligated, and it would therefore appear that most of the fluid seeps through the covering epithelium. Owing to the fibromatous nature of the tumour, it may be that the lymphatic and venous channels are obstructed, with resultant oedema. The present case illustrates that enormous quantities of fluid may be produced in a relatively short time, and one might be justified in describing the ovarian tumour as a sort of pump, collecting fluid from the circulation and diverting it into the peritoneal cavity.

Although these speculations are of much theoretical interest, the point to be emphasized is that a clinical picture closely resembling that of advanced malignancy may have a benign aetiology. The dictum of Lawson Tait (1892) bears repetition : "There is an almost universal indication for laparotomy in abdominal disease."

I am grateful to Dr. A. L. Shivas for confirming that the tumour was a benign fibroma of the ovary.

\section{JAMES G. LAWSON, M.D., M.R.C.O.G.,} Midwifery Department, University of Aberdeen. REFERENCES

Lawson, J. G. (1950). J. Obstet. Gynaec. Brit. Emp., 57, 595. Tait, L. (1892). Med.-chir. Trans., 75, 109. 